\title{
Comparable effect of adipose-derived stromal vascular fraction and mesenchymal stem cells for wound healing: An in vivo study
}

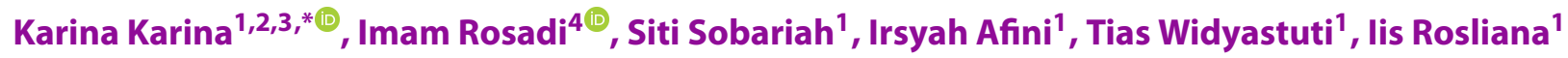

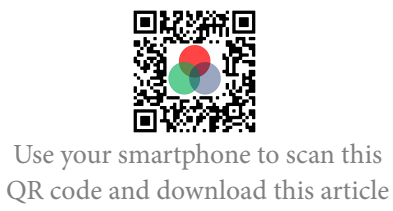

${ }^{1}$ HayandraLab, Yayasan Hayandra Peduli, Jakarta, Indonesia

${ }^{2}$ Klinik Hayandra, Yayasan Hayandra Peduli, Jakarta, Indonesia

${ }^{3}$ Doctoral Program of Biomedical Sciences, Universitas Indonesia, Jakarta, Indonesia

${ }^{4}$ Magister Program of Biotechnology Department, Institut Teknologi Bandung, Jawa Barat, Indonesia

\section{Correspondence}

Karina Karina, HayandraLab, Yayasan Hayandra Peduli, Jakarta, Indonesia

Klinik Hayandra, Yayasan Hayandra Peduli, Jakarta, Indonesia

Doctoral Program of Biomedical Sciences, Universitas Indonesia, Jakarta, Indonesia

Email: karina@hayandra.com

\section{History}

- Received: Jul 15, 2019

- Accepted: Sep 28, 2019

- Published: Oct 27, 2019

\section{DOI :}

https://doi.org/10.15419/bmrat.v6i10.570

\section{Check for updates}

\section{Copyright}

(C) Biomedpress. This is an openaccess article distributed under the terms of the Creative Commons Attribution 4.0 International license.

\section{BioMedPress}

The Open Access Publisher

\begin{abstract}
Introduction: Mesenchymal stem cells (MSCs) have been known to have angiogenic potency, particularly for wound healing. However, it is such a cumbersome procedure to obtain a large amount of MSCs due to the culture process. The stromal vascular fraction (SVF), or so called nonexpanded MSCs, of adipose tissue is gaining increased interest in the field of cell therapy. An optimized method that takes only 2 hours to produce a large amount of stromal cells from adipose tissue has been developed. Burn wound model was used to assess the efficacy of SVF produced by our method. This study aimed to evaluate the efficacy of SVF compared to MSCs. Methods: Male Sprague-Dawley rats with second degree burn wound were divided into the study groups: SVF, MSCs and saline control. The wound was photographed and evaluated weekly up to 5 weeks. The comparative analysis consisted of healing time, histology of skin tissue, as well as rat and human vascular endothelial growth factor (VEGF) expression. Results: In this study, wounds treated with SVF and MSCs were smaller after 14-21 days, compared to the untreated group. Expression of rat VEGF in SVF and MSC- treated groups after seven days post-wounded were also higher than the untreated group. No human VEGF was found expressed in the skin biopsies. Conclusion: This suggests that SVF and MSCs promote wound healing via a paracrine effect. The results suggest that SVF may be useful for wound healing and may be used as a promising alternative to MSC-based therapy.
\end{abstract}

Key words: Adipose, Stem cell, Stromal vascular fraction, Vascular endothelial growth factor, Wound healing

\section{INTRODUCTION}

Adipose tissue is a source of multipotent mesenchymal stem cells (MSCs), much like bone marrow. The tissue is derived from mesenchyme and contains several types of cells, such as pericytes, stem cells, endothelial cells, and their progenitors, smooth muscle cells, adipocytes and pre-adipocytes, and hematopoietic cells ${ }^{1}$. Zuk et al. termed the cells derived from adipose tissue as a stromal vascular fraction (SVF $)^{2}$. Determining optimal cell dose is important for successful cell therapy. Koga and his coworkers demonstrated that a dosage of 50 million MSCs per $\mathrm{mL}$ injected into cartilage defects in rabbit was a superior dose than 1 million MSCs per $\mathrm{mL}$ for cartilage repair $^{3}$. This result suggests that the amount of MSCs needed for humans might be somewhat larger than that reported for rabbits, especially for intravenous administration. The MSCs, whether they are bone marrow-derived or adipose tissue-derived, are often difficult to obtain in large amounts upon harvest. On the other hand, SVF can be easily obtained in a larger amount from lipoaspirates within only two hours, as has been previously demonstrated by our group ${ }^{4}$. Therefore, it seems promising to use SVF as an alternative to MSCs for clinical application.

In this study, we investigated the efficacy of SVF for burn wound healing in a rat model, with adiposederived MSCs (AD-MSCs) used in the comparison. Rat and human VEGF expression were measured to evaluate the angiogenic potency of SVF and MSCs.

\section{METHODS}

This study was conducted in a facility at the Animal Hospital of Bogor Agricultural Institute in compliance with an animal protocol that had been reviewed and approved by the Health Research Ethics Committee (at the University of Indonesia) and Cipto Mangunkusumo Hospital (HREC-FMUI/CMH), with letter no. 625/UN2.F1/ETIK/2016. Twenty-eight male Sprague-Dawley rats, aged 8-10 weeks old and with the body weight of 100-175 grams, were randomized into three groups: human SVF-treated group, MSC-treated group, and saline-treated group (as control). For the SVF collection, donors were patients of 
Klinik Hayandra Hospital with various health conditions who had signed an informed consent and had been recruited consecutively based on their treatment registration date. SVF was collected from each patient. Some of SVFs from each donor were cultured to obtain passage 1 MSCs to be used in the study.

\section{SVF Preparation}

SVF was prepared from fresh human lipoaspirates using the previously described method ${ }^{4}$. Tissuedissociation enzyme of H-Remedy was added to lipoaspirates in $50 \mathrm{~mL}$ tubes and incubated for 1 hour at $37^{\circ} \mathrm{C}$. After incubation, low glucose Dulbecco's Modified Eagle's Medium (DMEM) containing $4 \mathrm{mM}$ L-glutamine (Gibco/ Thermo Fisher Scientific, Waltham, MA) was added to inactivate the enzyme. Digested lipoaspirates in tubes were centrifuged for 5 minutes at $600 \mathrm{~g}$. Supernatants in all tubes were discarded, and SVF as cell pellets were collected, mixed with red cell buffer lysis, and incubated for 10 minutes at room temperature. After centrifugation, SVF was washed twice with phosphate buffer saline (PBS) of $\mathrm{pH}$ 7.4. SVF was diluted in saline solution and kept at $4^{\circ} \mathrm{C}$ for $1-3$ days prior to use.

\section{Culture of MSCs}

Some of the SVFs from donors were cultured in 25 $\mathrm{cm}^{2}$ flask at a cell density of 125,000 cells/flask until cells were attached at $37^{\circ} \mathrm{C}$. A combination of low glucose DMEM containing $4 \mathrm{mM}$ L-glutamine (Gibco/ Thermo Fisher Scientific, Waltham, MA) supplemented with 10\% FBS (Gibco), 1\% antibiotic/antimycotic solution (10,000 units/mL of penicillin, $10,000 \mu \mathrm{g} / \mathrm{mL}$ of streptomycin, and $25 \mu \mathrm{g} / \mathrm{mL}$ of Amphotericin B) (Gibco), and $0.05 \mathrm{ng} / \mathrm{mL} \mathrm{L-}$ ascorbic acid was added in the culture medium. The medium was replenished with fresh medium every 2-3 days. Cells were sub-cultured after they reached $80 \%$ confluency. Passage 1 MSCs were harvested and stored in saline solution at $4^{\circ} \mathrm{C}$ only for $1-3$ days before use.

\section{Characterization of MSCs}

\section{Cell Differentiation Assay}

MSCs ( $2 \times 10^{4}$ cells) were seeded in 24 -well plates and cultured. After cells reached $80 \%$ confluency, the culture medium was replaced with osteogenic, chondrogenic, and adipogenic medium, as described by the manufacturers (STEMPRO Osteogenesis, Chondrogenesis, and Adipogenesis Differentiation Kit; Gibco/ Thermo Fisher Scientific, Waltham, MA). Adipocyte, chondrocyte, and osteocytes can be detected by Oil
Red O (Sigma-Aldrich, Louis St, MO), Alcian Blue (Sigma-Aldrich), and Alizarin Red (Sigma-Aldrich) staining, respectively.

\section{Phenotyping Analysis}

Phenotyping analysis from two randomly selected MSC samples was done using 3-laser and 10channel multiparameter flow cytometer (Miltenyi Biotec Inc., Auburn, CA). Cell surface markers used were APC-labeled mouse anti-human CD73, FITClabeled mouse anti-human CD90, PerCP Cy5.5labeled mouse anti-human CD105 (as a positive MSC marker), and a cocktail marker consisting of CD34, CD45, CD11b, CD19, and HLA-DR (PE-conjugated) as positive hematopoietic cells markers (Becton Dickinson, Franklin Lakes, NJ). Antibody titration was performed before the analysis to determine the antibody amount and concentration that produces the lowest signal of the negative population and highest signal of the positive population- in order to reduce nonspecific antibody binding. Unstained cells and isotype antibody were used as control. Debris was excluded from analyzed cells. The results represented a collection of 10.000 events per analyzed sample.

\section{Second Degree Wound Healing Model and Tr ansplantation}

A wound healing model by Zhang et al. ${ }^{5}$ was used as a reference with minor modifications. After 1 week of the adaptation period, rats were injected intraperitoneally with ketamine and xylazine $(0.1 \mathrm{~mL} / 20 \mathrm{~g}$ of rat body weight). The shaved back of the rats were contacted for 4 seconds with a flat-round bottom stainless steel (200 g) that have been previously incubated in boiled water for 5 minutes. Five hundred $\mu \mathrm{L}$ of SVF in saline solution ( $4 \times 10^{7}$ cells per rat) or MSCs in saline solution ( $4 \times 10^{5}$ cells per rat) from the same donors, or saline as a control, were injected intradermally to the back of the rat.

Transplantations were done in two rounds: the first round was for SVF transplantation, and the second round was for MSC transplantation. There were 6-8 weeks apart between SVF and MSC transplantation for MSC culture. However, in this study, we were not able to obtain $4 \times 10^{5}$ MSCs from 4 of 8 donors due to long population doubling time, but from each of the rest of the donors, we were able to culture MSCs in sufficient numbers for transplantation in two rats. In this study, one rat received SVF/MSCs from one donor, but there were SVF/MSCs from 4 donors for which each was transplanted in two rats. The total rats receiving SVF, MSCs, and saline injection were 
12,8 , and 8 , respectively. Rats were fed ad libitum up to 5 weeks. For real-time polymerase chain reaction (PCR) analysis, 4 rats in the SVF-treated and 4 rats in the MSCs-treated groups, as well as 2 rats in the control group, were killed on day 7 and the skin collected. After 5 weeks (35 days), there were 8, 4, and 6 rats in the SVF, MSCs, and control group, respectively, that remained for the weekly micro- and macro-scopic evaluations.

\section{Wound Healing Analysis Macroscopic evaluation}

The wound was inspected weekly, photographed and evaluated by image analysis software (Image J; National Institute of Health, Bethesda, MD, USA) to measure the wound area by two blinded investigators. The percentage of wound area was quantified by dividing the measured wound area post-wounded with the baseline wound area (taken on day 0 ) to measure closure rates between treatment groups.

\section{Microscopic evaluation}

At the end of the study (week 5), rats were euthanized. All rats were killed using the cervical dislocation technique. The entire wound with intact skin was collected and subjected to histological analysis by hematoxylin-eosin (H\&E) staining. Tissue regeneration was analyzed based on re-epithelialization, the presence of skin appendages (hair follicle and sebaceous gland), structure, and thickness of the dermis.

\section{Real-time Analysis of VEGF Expression}

At day 7, wounded skin tissue of 2-4 rats from each group was randomly collected and subjected to measurement of rat and human VEGF expression by realtime PCR method.

In brief, total ribonucleic acid (RNA) from tissue was extracted using QIAamp RNA Blood Mini Kit (Qiagen, Germantown, MD, USA) according to the manufacturer's protocol. The concentration and quality of RNA were measured using a spectrophotometer. Complementary DNA (cDNA) was synthesized from RNA by QuantiTect Reverse Transcription Kit (Qiagen). The resultant cDNA was subjected to quantitative real-time PCR (qPCR) performed using QuantiTect SYBR Green PCR Kit (Qiagen). Primer sequences were designed to be specific for rats or humans. The primer sequences of VEGF from rat were 5'-GTGTGGTCTTTCGTCCTTCTTA-3' (forward) and 5'-GTTTGTCGTGTTTCTGGAAGTG3' (reverse), and for human were 5'GAGCTTCCTACAGCACAACA-3' (forward) and

5'-CCAGGACTTATACCGGGATTTC$3^{\prime}$ (reverse). $\quad \beta$-actin primer sequences were used as internal controls and were 5'GTGTGGATTGGTGGCTCTATC-3' (forward) and 5'-CAGTCCGCCTAGAAGCATTT-3' (reverse) for the rat, and 5'-CACTCTTCCAGCCTTCCTTC-' 3 (forward) and 5'-GTACAGGTCTTTGCGGATGT-3' (reverse) for human. The following qPCR protocol was employed: 40 cycles of denaturation at $94^{\circ} \mathrm{C}$ for $15 \mathrm{sec}$, annealing at $57{ }^{\circ} \mathrm{C}$ for $30 \mathrm{sec}$, and extension at $72^{\circ} \mathrm{C}$ for $30 \mathrm{sec}$. The single melting curve results confirmed there was no unspecific reaction during amplification. Relative mRNA expression was quantified by dividing gene expression from SVF or MSC-treated samples to untreated control sample.

\section{Statistics}

Data were tested for normal distribution and equal variance. Differences between experimental groups were then calculated by analysis of variance (ANOVA) followed by the least significant difference post hoc analysis or Kruskal-Wallis, followed by MannWhitney $U$ test for normal distribution with equal variance and non-normal distribution or unequal variance data. ANOVA for repeated measures was applied to test for time effects within each experimental group. Wound areas were represented as mean \pm SEM. Statistical significance was accepted if $p<0.05$.

\section{RESULTS}

\section{Donor Demographics}

SVF was obtained from 6 female and 2 male donors that were SVF patients with various health conditions (5 patients with no pathological condition, 2 patients with musculoskeletal disorders, and 1 patient with autism). The mean age of the donor was $59 \pm 14$ years old, with a range of 34-75 years old.

\section{Cultured MSCs from Isolated SVFs}

According to the International Society of Cellular Therapy (ISCT), most MSCs should express high levels of CD73, CD90 and CD105 (more than 95\%) and low (less than 2\%) levels of CD34, CD45, CD11b, CD19, and HLA-DR, as these are expressed in hematopoietic cells. In this study, $99 \%$ of our plastic adherent, fibroblast-like MSCs expressed CD73 and CD90, and did not express CD34, CD45, CD11b, CD19 or HLA-DR (Figure 1). However, the MSCs did not express CD105 as high as MSCs derived from bone marrow, as defined by the ISCT. 

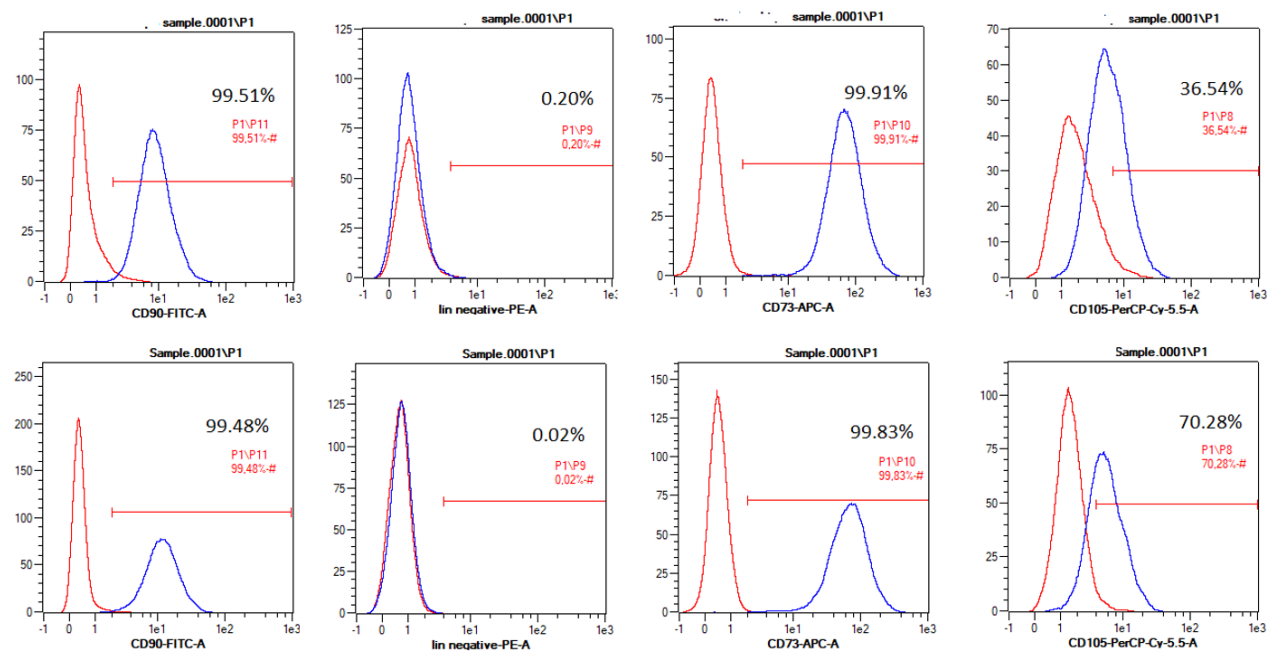

Figure 1: Representative expression of CD73, CD90, CD105, and lineage negative surface markers (CD34/CD45/CD11 b/CD19/HLA-DR) in cultured MSCs from two donors. Red curve represents isotype as negative signal control and blue curve represents cells stained with fluorochrome-conjugated antibodies.
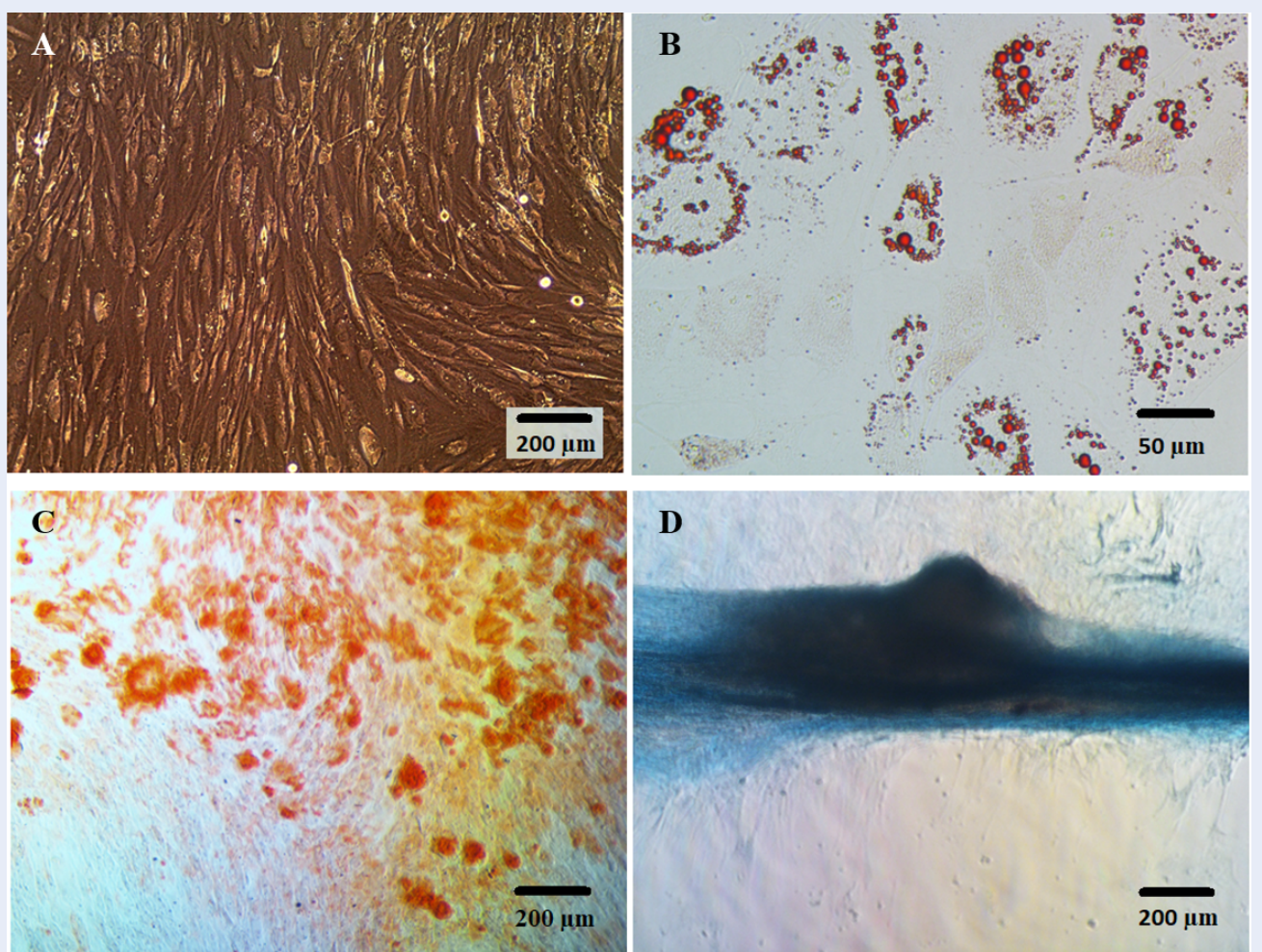

Figure 2: MSCs showed differentiation into adipocytes (B), osteocytes (C), and chondrocytes (D), and exhibited a different morphology compared to undifferentiated MSCs (A). 
All of our cultured MSCs were shown to be able to differentiate into adipocytes, osteocytes and chondrocytes over the 4-day induction period by common differentiation medium, as shown in Figure 2.

\section{Efficacy of SVF and MSCs in Wound Healing}

The efficacy of each treatment was analyzed based on the percentage of wound area measured over a 5-week period, as presented in Figure 4. On day 7, the MSCtreated group had an average wound area that was larger than baseline. After 7 days and onward, the wound area was reduced in all groups, and there was no statistical difference observed between the treated groups (SVF or MSCs) versus the untreated group. The wound closure rate was faster in SVF-treated or MSC-treated group, compared to untreated group, during the 14-21 day period; the wound in the MSCtreated group closed slightly faster than that of the SVF-treated group. However, there was no significant difference between MSC- or SVF-treated groups on day 21 . On day 28 , the area of the wound was reduced to about $20 \%$ in all groups. At the end of the study, the wound area in the MSC-treated group was significantly larger than that of the SVF-treated or untreated group. The macroscopic change of the wound, weekly up to 35 days post-wound, is shown in Figure 3.

\section{Histopathological Examination of Skin Tis- sue \\ Re-epithelialization}

After 35 days, the epidermis layer in the SVF- and MSC-treated groups were thicker than that of the untreated group. The average length of skin layer that had not been covered by epithelial layer in the SVFtreated group was $6.73 \pm 0.26 \mathrm{~mm}$, while in the MSCtreated group it was $6.68 \pm 0.98 \mathrm{~mm}$. The untreated group had the longest layer that was uncovered by epithelium $(10.41 \pm 5.01 \mathrm{~mm})$.

\section{Dermis layer}

After 35 days, there was no significant difference in thickness of dermal layer between the groups (993.15 $\pm 129.09 \mu \mathrm{m}$ for saline, $1148.78 \pm 34.30 \mu \mathrm{m}$ for SVF treated group, and $1108.79 \pm 166.53 \mu \mathrm{m}$ for MSCs treated group; $p>0.05$ ). However, the dermis layer in the SVF- and MSC-treated groups were dense compared to that of the untreated group (Figure 5).

\section{Skin Appendages}

Hair follicles and sebaceous glands were present in all groups. However, hair follicles and sebaceous glands were more prominent (and each of these was larger) in SVF- and MSC- treated groups compared to the untreated group, especially in skin sections where the skin was completely covered by epithelium.

\section{Measurement of VEGF Expression in Skin Tissue}

We measured the expression of VEGF, an angiogenic growth factor that plays a key role in wound healing. Samples were obtained after 7 days postwounded when the proliferative phase was assumed. On day 7, VEGF expressions in treated groups (SVF and MSCs) were increased compared to the untreated group but were not significantly different when statistically examined. There was no significant difference found between VEGF expression in SVF- and MSCtreated groups $(1.74 \pm 1.50$ for SVF-treated group versus $1.79 \pm 0.40$ for MSC-treated group, $\mathrm{p}=0.96$ ) (Figure 6).

We also analyzed the expression of human VEGF in skin tissue samples to detect the presence of VEGF from SVF and MSCs. However, in this study, we did not find any expression of VEGF from SVF or MSC donor in skin tissue taken on day 7 post-wounded.

\section{DISCUSSION}

We demonstrated that SVF could be easily isolated from adipose tissue. By culturing the cells, we observed that MSCs were present in SVF in this study. Our cultured MSCs from donors aged 50-60 years old showed fibroblast-like morphology and ability to adhere to plastic, similar to other reported studies ${ }^{6,7}$. Expression of CD73 and CD90 in our cultured MSCs was observed in almost all cells (close to 100\%). Our results are similar to those reported by the ISCT to be expressed in bone marrow-derived $\mathrm{MSCs}^{8}$. The ISCT describes that more than $95 \%$ of MSCs express CD105 (very high percentage). However, in this study, we found that our highest percentage of $\mathrm{CD}_{105^{+}}$cells was only $70 \%$. Another study also found similar results; the donor ages were from $50-60$ years old, and the percentage of MSCs with CD105 expression was about $70-80 \%{ }^{9}$. No clear mechanism has been reported for the lower CD105 expression in MSCs. However, since the ISCT set is the criteria for bone-marrow derived MSCs, CD105 expression in bone-marrow derived MSCs may differ from those expressed in adipose-derived MSCs. Indeed, the differences in surface marker expression of MSCs derived from bone marrow versus adipose tissue have been reported previously by other studies ${ }^{9,10}$.

In this study, we found that SVF and MSCs from elderly donors promote second degree burn wound 


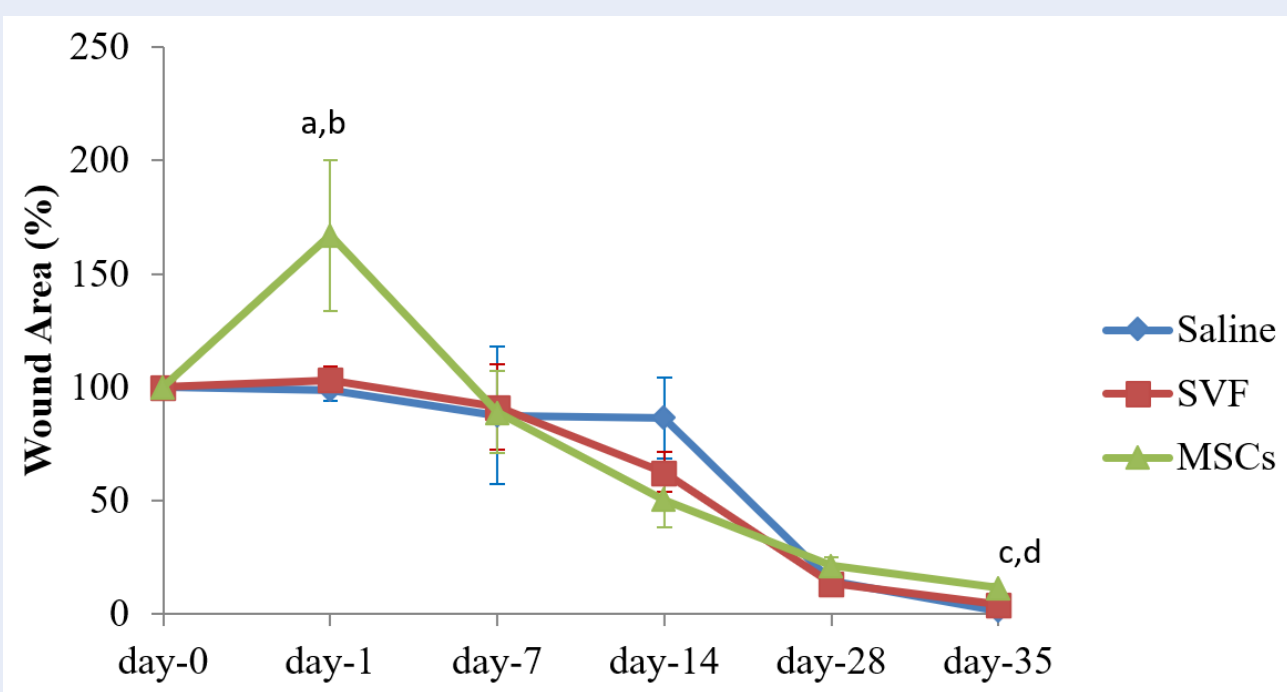

Observation Schedule

Figure 3: Wound healing rate of each treatment. On day 7 , the wound area in the MSC-treated group $(n=4)$ was significantly larger than that of the SVF-treated group $(n=8)$ or untreated group $(n=6) ; p=0.002$ compared to SVF (A), and $p=0.001$ compared to untreated group (B). The same findings were also observed at the end of study; $p<0.001$ compared to both SVF (C) and untreated group (D)). Data are presented as mean $\pm \mathrm{SEM}$.

healing during the 14-21 day period post-wound in the rat model, compared to untreated rats. Both SVF and MSC treatments were able to increase the expression of VEGF, an angiogenic growth factor that is important for wound healing. This paracrine effect has been reported in other wound healing studies. Hosni and coworkers reported that TGF- $\beta 1$, another important angiogenic growth factor, was increased in rat skin after MSC treatment ${ }^{11}$. Similar results have also been reported by Lee et al. ${ }^{12}$. Moreover, Carolina et al. reported that plasma TGF- $\beta$ level was increased in severe burn rat treated with MSCs ${ }^{13}$. These data concluded that upregulation of angiogenic growth factors, such as VEGF and TGF- $\beta$, are needed in the inflammatory and proliferative phases during wound healing, as well as in neo-vascularization and skin remodeling ${ }^{14}$. However, we were unable to find a significant difference between SVF- and MSC-treated groups. We also observed that the standard deviation of VEGF levels in SVF-treated group was higher compared to that of the MSC-treated group. These are probably due to the heterogeneity of cells within SVFs, compared to MSCs, which have already gone through the purification process (eliminating nonadherent cells and enriching for cells that are positive for CD73, CD90, and CD105 expression) during cell passaging. We also did not observe any expression of human VEGF on skin tissue after 7 days post-wound.
It has known that MSCs are often stressed and begin to die after being transplanted, releasing various cytokines and growth factors beneficial for wound healing ${ }^{15}$.

In this study, we did not find any significant difference between the SVF- and MSC-treated groups. This may be due to the heterogeneity of SVF composition and MSC-associated biological functions, such as CD105 expression and MSC proliferation. In regards to SVF composition, endothelial cells, progenitor cells, and immune cells within SVF may have synergistic interactions with MSCs for promoting wound healing. Another possible reason is that MSCs in this study were obtained from other elder donors with unstandardized health conditions.

Our flow cytometry data analysis revealed that MSCs in this study have CD105 expression that is less than 95\%. CD105 is an accessory protein that interacts with the receptor for pro-angiogenic TGF- $\beta$. Therefore, lower CD105 expression by MSCs may reduce angiogenic potency resulting in lower wound healing rate, as reported in this study. Another study reported that MSCs with CD105 expression more significant than $95 \%$ and combined with platelet-rich plasma (PRP) could rapidly heal damaged mouse knee joints when compared to control or PRP alone ${ }^{16}$. These data suggest that for clinical applications, MSCs should express CD105 at a higher level than MSCs in this study. 


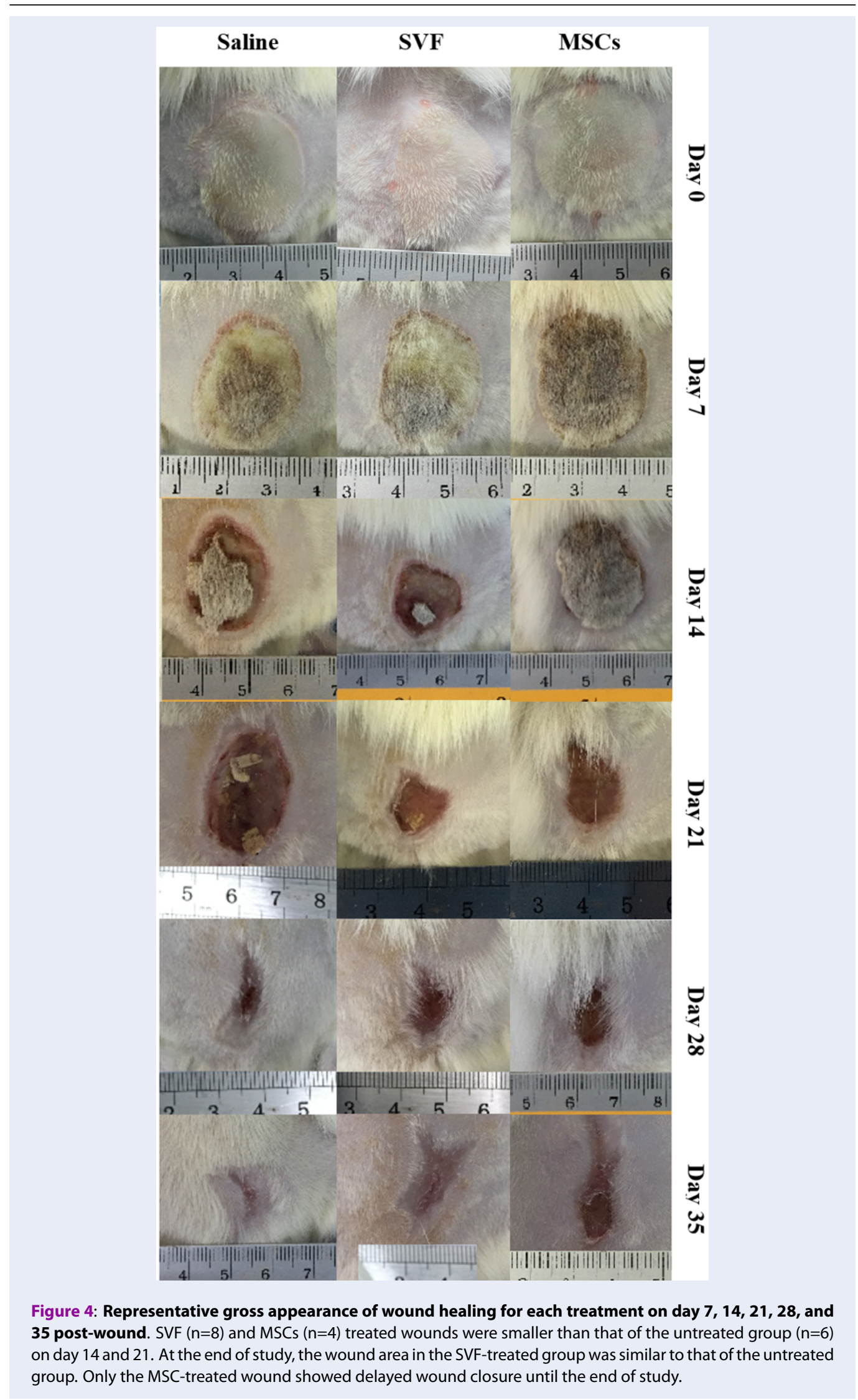




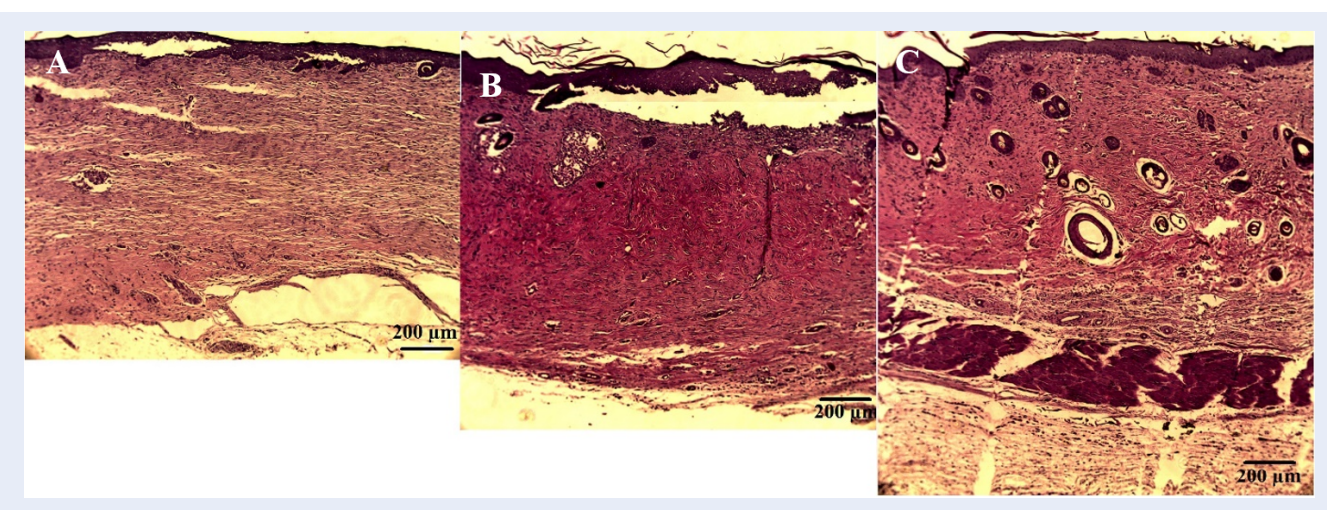

Figure 5: Representative image of skin layer from each group. (A) untreated group, (B) SVF-treated group, and (C) MSC-treated group. Images were taken under a light microscope with 100X magnification.

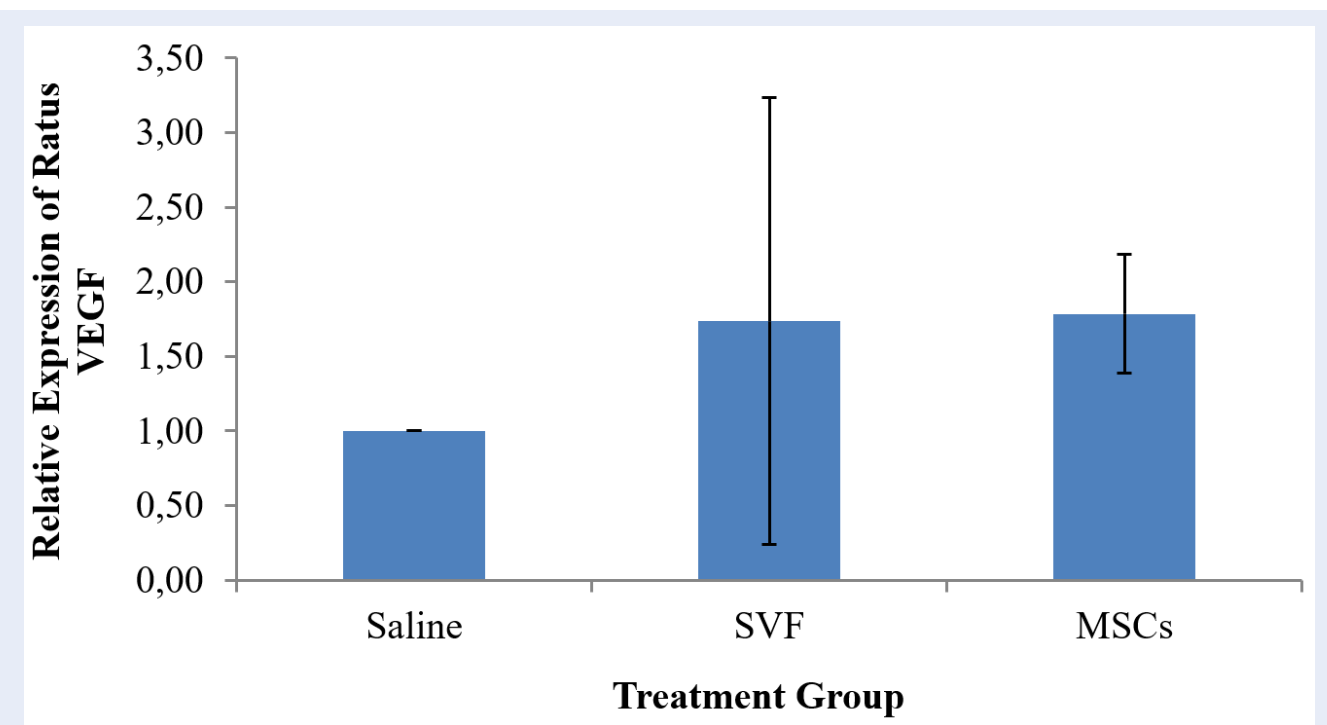

Figure 6: Comparison of rat VEGF expression in skin biopsies of SVF $(n=4)$, MSC-treated group $(n=4)$ and control group $(n=2)$ after 7 days post-wounded.

High CD105 expression in MSCs can be achieved from healthy and young donors. Therefore, selecting MSC donors is essential in successful cell therapy; this was not applied in our study and might represent and explain the limitation of our study. However, a study that is designed to mimic this actual condition of selecting healthy and young donors cannot be done in autologous stem cell therapy.

In some conditions, such as the case of autologous therapy for the elderly or people with diabetes or other pathological conditions, effective cell therapy still may be achieved by increasing the injected MSC number. However, this approach presents a new problem. For instance, MSCs from elderly or non-healthy patients have a low proliferative capacity, as has been observed in past studies ${ }^{9,17,18}$. Therefore, it is necessary to culture MSCs for more extended periods. However, extended in vitro culture of MSCs have the potential to reduce the stemness, multipotency and therapeutic effectiveness in cartilage repair of MSCs when combined with a $3 \mathrm{D}$ matrix ${ }^{19}$. Therefore, advanced culture methods or technologies are needed to maintain the quality of MSCs and to prevent MSCs from undergoing senescence or apoptosis. On the other hand, SVF can be easily obtained in large numbers, varying between $1-10$ billion cells from $50-250 \mathrm{cc}$ of adipose tissue, from patients of any age and health condition (except for malignancies) within 2 hours. These have been demonstrated by our previous study ${ }^{4}$. 


\section{CONCLUSION}

Both SVF and MSCs can promote wound healing in second degree burn wound model. SVF can be used as a promising alternative to MSCs as it is easier and faster to isolate a larger number of SVF compared to MSC preparation.

\section{ABBREVIATIONS}

AD-MSCs: adipose-derived MSCs

ANOVA: analysis of variance

cDNA: complementary DNA

DMEM: Dulbecco's Modified Eagle's Medium

ISCT: international society of cellular therapy

MSCs: mesenchymal stem cells

PBS: phosphate buffer saline

PRP: platelet-rich plasma

qPCR: quantitative polymerase chain reaction

RNA: ribonucleic acid

SVF: stromal vascular fraction

VEGF: vascular endothelial growth factor

\section{COMPETING INTERESTS}

The authors indicated no potential conflicts of interest.

\section{AUTHORS' CONTRIBUTIONS}

Conception and design: KRN, IRA, IRI; contribution in cell culture works: SSH, IAI, TWI; data collection and entry: SSH, IRA, IRI, IAI, TWI; data analysis and interpretation: KRN, IRA, IRI; manuscript writing: KRN, IRA; final approval of manuscript: KRN, IRI, IRA.

\section{ACKNOWLEDGMENTS}

The authors would like to thank Prof. dr. Jeanne Adiwinata Pawitan, MS, PhD for guiding the laboratory work and Komite Akreditasi Nasional-certified Laboratorium Terpadu Fakultas Kedokteran Universitas Indonesia for conducting real time PCR analysis for our samples used in this study.

\section{REFERENCES}

1. Zuk PA, Zhu M, Ashjian P, Ugarte DAD, Huang Jl, Mizuno $H$, et al. Human adipose tissue is a source of multipotent stem cells. Molecular Biology of the Cell. 2002;13(12):4279-95. PMID: 12475952. Available from: 10.1091/mbc.e02-02-0105.

2. Zuk PA, Zhu M, Mizuno $H$, Huang J, Futrell JW, Katz AJ, et al. Multilineage cells from human adipose tissue: implications for cell-based therapies. Tissue Engineering. 2001;7(2):211-28. PMID: 11304456. Available from: 10.1089/ 107632701300062859.

3. Koga H, Muneta T, Nagase T, Nimura A, Ju YJ, Mochizuki T, et al. Comparison of mesenchymal tissues-derived stem cells for in vivo chondrogenesis: suitable conditions for cell therapy of cartilage defects in rabbit. Cell and Tissue Research. 2008;333(2):207-15. PMID: 18560897. Available from: 10. 1007/s00441-008-0633-5.
4. Remelia M, Rosadi I, Rosliana I, Sobariah S. Karina. Optimized method for isolation of regenerative stromal cells from human lipoaspirates. In: The 3rd International Conference of Innovations in Cancer Research and Regenerative Medicine. Vietnam: Viet Nam University of Science, VNUHCM; 2017.

5. Zhang X, Wei X, Liu L, Marti GP, Ghanamah MS, Arshad MJ, et al. Increasing burn severity in mice is associated with delayed mobilization of circulating angiogenic cells. Archives of Surgery (Chicago, III). 2010;145(3):259-66. PMID: 20231626. Available from: 10.1001/archsurg.2009.285.

6. Pawitan JA, Liem IK, Suryani D, Bustami A, Purwoko RY. Simple lipoaspirate washing using a coffee filter. Asian Biomedicine. 2013;7(3):333-8.

7. Pham PV, Bui KHT, Ngo DQ, Khuat LT, Phan NK. Transplantation of nonexpanded adipose stromal vascular fraction and platelet-rich plasma for articular cartilage injury treatment in mice model. Journal of Medical Engineering. 2013;2013:832396. PMID: 27006923. Available from: 10.1155/ 2013/832396.

8. Dominici M, Blanc KL, Mueller I, Slaper-Cortenbach I, Marini $F$, Krause $D$, et al. Minimal criteria for defining multipotent mesenchymal stromal cells. The International Society for Cellular Therapy position statement. Cytotherapy. 2006;8(4):315-7. PMID: 16923606. Available from: 10.1080/ 14653240600855905 .

9. Maredziak M, Marycz K, Tomaszewski KA, Kornicka K, Henry $B M$. The influence of aging on the regenerative potential of human adipose derived mesenchymal stem cells. Stem Cells International. 2016;2016:2152435. PMID: 26941800. Available from: 10.1155/2016/2152435.

10. Pawitan JA, Wulandari D, Suryani D, Damayanti L, Purwoko RY, Liem IK. Flow cytometry analysis of adipose tissue-derived stem cells that were cultured in various media. International Journal of Pharm Tech Research. 2013;5(3):1301-6.

11. Ahmed $H H$, Rashed LA, Mahfouz $S$, Hussein RE, Alkaffas $M$, Mostafa S, et al. Can mesenchymal stem cells pretreated with platelet-rich plasma modulate tissue remodeling in a rat with burned skin? Biochemistry and Cell Biology. 2017;95(5):53748. PMID: 28314112 . Available from: 10.1139/bcb-2016-0224.

12. Lee DE, Ayoub N, Agrawal DK. Mesenchymal stem cells and cutaneous wound healing: novel methods to increase cell delivery and therapeutic efficacy. Stem Cell Research \& Therapy. 2016;7(1):37. PMID: 26960535. Available from: 10.1186/ s13287-016-0303-6.

13. Caliari-Oliveira C, Yaochite JN, Ramalho LN, Palma PV, Carlos $\mathrm{D}$, Cunha FQ, et al. Xenogeneic mesenchymal stromal cells improve wound healing and modulate the immune response in an extensive burn model. Cell Transplantation. 2016;25(2):201-15. PMID: 25955320. Available from: 10.3727/ 096368915 X688128.

14. Johnson KE, Wilgus TA. Vascular endothelial growth factor and angiogenesis in the regulation of cutaneous wound repair. Advances in Wound Care (New Rochelle, NY). 2014;3(10):64761. PMID: 25302139. Available from: 10.1089/wound.2013. 0517.

15. Muhammad G, Xu J, Bulte JW, Jablonska A, Walczak P, Janowski M. Transplanted adipose-derived stem cells can be short-lived yet accelerate healing of acid-burn skin wounds: a multimodal imaging study. Scientific Reports. 2017;7(1):4644. PMID: 28680144. Available from: 10.1038/s41598-017-044840.

16. Pham PV, Bui KH, Ngo DQ, Doan TT, Vu NB, Truong NH. Expanded Adipose Tissue-Derived Stem Cells for Articular Cartilage Injury Treatment: A Safety and Efficacy Evaluation. In: Bhattacharya N, Stubblefield P, editors. Regenerative Medicine. London: Springer; 2015. Available from: 10.1007/ 978-1-4471-6542-2 11.

17. Peng C, Ma J, Gao X, Tian P, Li W, Zhang L. High glucose induced oxidative stress and apoptosis in cardiac microvascular endothelial cells are regulated by FoxO3a. PLoS One. 2013;8(11):e79739. PMID: 24260294. Available from: 10.1371/ journal.pone.0079739. 
18. Ko KI, Coimbra LS, Tian C, Alblowi J, Kayal RA, Einhorn TA, et al. Diabetes reduces mesenchymal stem cells in fracture healing through a TNF $\alpha$-mediated mechanism. Diabetologia. 2015;58(3):633-42. PMID: 25563724. Available from: 10.1007/s00125-014-3470-y.
19. Jiang $T$, $X u G$, Wang $Q$, Yang $L$, Zheng $L$, Zhao J. In vitro expansion impaired the stemness of early passage mesenchymal stem cells for treatment of cartilage defects. Cell Death \& Disease. 2017;8(6):e2851. PMID: 28569773. Available from: 10.1038/cddis.2017.2. 